\title{
Effects of Terazosin and Tolterodine on Ureteral Stent Related Symptoms: A Double-Blind Placebo-Controlled Randomized Clinical Trial
}

\author{
Ali Tehranchi, Yousef Rezaei, Hamidreza Khalkhali, Mahdi Rezaei \\ Department of Urology (AT), Urmia Urology and Nephrology Research Center, Research Committee (YR); \\ Department of Biostatistics and Epidemiology (HK), Urmia University of Medical Sciences, Urmia, Iran and \\ Department of Toxicology (MR), Pharmaceutical Sciences Branch, Islamic Azad University, Tehran, Iran
}

\begin{abstract}
Objective: To evaluate the effects of terazosin and tolterodine on ureteral stent discomfort. Materials and Methods: Of 163 patients assessed for eligibility, 104 patients were randomly assigned to receive placebo, $2 \mathrm{mg}$ of terazosin twice daily, $2 \mathrm{mg}$ of tolterodine daily, or both terazosin plus tolterodine during the stenting period. Prior to stenting and at stent removal, the International Prostate Symptom Score (IPSS), the IPSS quality of life $(\mathrm{QoL})$ subscore and the Visual Analog Scale for Pain were determined. The patients also reported their analgesic use during the stenting period.

Results: Ninety-four patients completed the study. We noted significant decreases in the total IPSS scores $(p=0.002)$, irritative subscore $(p=0.039), Q o L(p=0.001)$, flank pain ( $p$ $=0.013)$, voiding pain $(p=0.01)$ and amount of analgesics used $(p=0.02)$ in the groups. However, neither the obstructive subscore nor the suprapubic pain improved significantly $(p=0.251$ and $p=0.522$, respectively). The patients receiving terazosin plus tolterodine experienced significant reductions in the total IPSS, irritative symptoms, QoL, flank pain, voiding pain and decreased analgesics use compared with those patients receiving placebo. However, compared with placebo, terazosin monotherapy did not affect pain levels, and tolterodine monotherapy did not improve QoL, flank pain or analgesics use.

Conclusions: Terazosin plus tolterodine improves ureteral stent-related complications, including irritative symptoms, the amount of analgesics used, QoL, flank pain and voiding pain but does not decrease obstructive symptoms or suprapubic pain. This trial was registered at www.clinicaltrials.gov as NCT01530243.
\end{abstract}

\section{ARTICLE INFO}

\section{Key words:}

Ureter; Stents; Complications [Subheading]; Adrenergic Alpha-antagonists; Cholinergic Antagonists

Int Braz J Urol. 2013; 39: 832-40

Submitted for publication:

May 17, 2013

Accepted after revision:

August 15, 2013

\section{INTRODUCTION}

Ureteral stents are essential tools in urology and those indications have dramatically increased (1). The ureteral stents are important in treating urolithiasis; however, despite innovations and improvements, they are associated with some morbidity (2). Multiple studies have determined stent-related discomforts including urinary symptoms; flank, supra pubic and voiding pain; stent displacement and encrustation (1-5).

Some etiologies have been hypothesized for their complications including mechanical irritation of the bladder trigone, urine renal reflux resulting obstruction, bacterial colonization, stent positioning as well as stent size and design (1,3,6- 
10). Strategies for managing stent complications include accurate stent indications, stenting maneuvers, stent design and use of medications $(1,3)$.

Recent studies have shown that alpha-blockers and anticholinergics could alleviate urinary symptoms caused by overactive bladder and benign prostatic hyperplasia (11-13). The similarity between stent-related urinary symptoms and conditions including overactive bladder syndrome and benign prostatic hyperplasia is main reason for using those to treat stent-related symptoms $(6,14)$. Given these notions, some studies have demonstrated the impacts on stent-related discomforts $(14,15)$. The objective of this trial was to determine the effectiveness of terazosin and tolterodine in improving the stent-related symptoms in patients undergoing unilateral stenting.

\section{MATERIALS AND METHODS}

This prospective, double-blinded and placebo-controlled randomized trial was conducted in West Azerbaijan, Iran. The study was approved by our local ethical committee; all patients provided informed consent to participate in this investigation. Data were collected in a referral hospital and analyzed by our research center (Urmia Urology and Nephrology Research Center) statistician. This trial was registered at www.clinicaltrials.gov as NCT01530243.

From February 2012 to August 2012, patients with ureteral and/or renal calculi undergoing urolithiasis therapy using transurethral lithotripsy (TUL) or percutaneous nephrolithotomy (PCNL) were assessed for eligibility. Patients who were 18-55 years old with stone size $\leq 20 \mathrm{~mm}$ and underwent unilateral ureteral stenting entered in this trial. The exclusion criteria included indwelling ureteral stent over the past 3 months, a history of pelvic or gynecologic surgery, transurethral resection of the prostate or a bladder tumor, chronic consumption of alpha-blocker and/or anticholinergic, recent or recurrent urinary tract infection, benign prostate hyperplasia, prostatitis, prostate cancer, bladder outlet obstruction, diabetes and pregnancy.

The patients were randomized in one of four groups in a $1: 1: 1: 1$ ratio using random-number table. The drugs were packed in boxes by a pharma- cologist; the boxes, labeled with the group numbers as "1", "2", "3" or "4", had the same shape and style, but each box had its own consumption order. After being randomized, the patients received numbered boxes containing unnamed drugs and were informed about drugs' side-effects without attention to the groups' number. The participants and physicians who prescribed drugs were blinded to the type of medications.

The patients were randomly assigned to receive a placebo (group 1), $2 \mathrm{mg}$ of terazosin twice daily (group 2), $2 \mathrm{mg}$ of tolterodine daily (group 3) or $2 \mathrm{mg}$ of terazosin twice daily plus tolterodine once a day (group 4). Moreover, they were prescribed a single dose of parenteral analgesic after surgery to alleviate post-operative pain and also received fifty $500 \mathrm{mg}$ acetaminophen tablets for pain control during the stenting period. Based on the policy at our institution they were prescribed $250 \mathrm{mg}$ of ciprofloxacin as a prophylactic antibiotic during seven days after stenting.

A semirigid ureteroscopy was performed using a Wolf 6Fr/7.5Fr (Richard Wolf, Knittlingen, Germany) and then intracorporeal lithotripsy was performed using a pneumatic lithotripter. The ureteral stents were positioned under direct vision with a Wolf $8 \mathrm{Fr} / 9.8 \mathrm{Fr}$ semirigid ureteroscope after the TUL or with a nephroscope after the PCNL. All PCNL procedures were performed using 24 Fr nephroscope and were tubeless. A $4.8 \mathrm{Fr}$ and $28 \mathrm{~cm}$ double-J stent (Urotech, Achenmühle, Germany) was deployed in all patients, and its position was verified by either fluoroscopy at the end of nephrolithotomy or controlled X-ray imaging following stenting. They received perioperative antibiotic regimen as single dose of parenteral cephalosporin, and had negative urine cultures pre-procedure, but those were not checked at the stent removal. Stent removing was performed using 19.5 Fr rigid cystoscope. They were also assessed using ultrasonographic investigation to evaluate stone-free rate at stent removal and if there were any stones, therefore, they underwent ancillary procedures including extracorporeal shock wave lithotripsy or ureteroscopic procedure.

Before stenting and at stent removal time, the patients were asked to complete the questionnaire and the Visual Analog Scale assessing stent-related discomforts. The pain was evaluated in the 
flank, suprapubic area and during micturition. We also asked the patients to record the amount of analgesics that they consumed and drug side-effects. Analgesics use was defined as the number of 500 $\mathrm{mg}$ acetaminophen tablets that the patients ingested at follow-up period.

Given a mean difference of 3.5 in the total IPSS score (mean of total IPSS score of three treatment groups minus mean of control group) and 4.5 SD among the groups based on the study of Lim and coworkers (15), the sample size was calculated as 26 patients per groups with a statistical power of 80\%. A Chi-squared test, one-way ANOVA, Tukey HSD test, the Kruskal-Wallis test (due to skewed distribution of data) and multiple comparison rank-sum tests were used, as appropriate; $p<0.05$ was considered statistically significant. Also, we analyzed TUL patients alone, since PCNL patients might influence our outcomes in terms of urinary symptoms or flank pain. Statistical analysis was performed using the SPSS software, version 16.0 (SPSS Inc., Chicago, IL, USA) and the Excel software (Microsoft Excel 2007).

\section{RESULTS}

Out of 163 patients who were assessed for eligibility, 104 patients who gave consent were randomly assigned to the groups. 94 (90.4\%) completed the study and the recruitment rate was $63.8 \%$. All of the 94 patients answered the questionnaire, but 2 patients (2\%) did not report the amount of painkillers consumed. Two patients $(1.9 \%)$ were excluded from the study because of stent displacement and having a history of gynecologic surgery, and eight patients (7.7\%) discontinued treatment due to lack of drug efficacy, fasting (religious belief), withdrawing the consent, intolerable pain, protocol deviation, and being lost at follow-up (Figure-1). The baseline and clinical characteristics are summarized in Table-1.

Nineteen patients $(20.2 \%)$ were female and average patients' age was $36.53 \pm 9.53$ years (1855 years), and the difference was not significant $(p=0.756)$. The mean stone size was $10.46 \pm 4.8$ $\mathrm{mm}$ in all patients (Table-1). The stone location was divided into two groups: ureteral and renal stones that showed no significant difference $(\mathrm{p}=$ 0.365). Eighteen patients (19\%) underwent PCNL and TUL was performed in seventy-six patients (81\%), $\mathrm{p}=0.221$.

We found no significant difference in the baseline total IPSS scores among the groups. The differences between mean irritative subscore (i.e. frequency, urgency and nocturia) and obstructive subscore (i.e. incomplete emptying, intermittency, weak-stream and straining) at baseline were not statistically significant $(p=0.661$ and $p=0.600$, respectively). However, significant differences in the total IPSS score and the irritative subscore at the stent removal time among the groups were seen, although there was no significant difference in the obstructive subscore at that time (Table-2). The mean quality of life (QoL) at baseline was similar among the groups; however, the QoL at the removal time was significantly lower in the combined-therapy compared with the other groups and its mean difference was statistically significant $(p=0.001)$.

The mean pain scores before stenting were not significantly different $(p=0.648)$; however, the flank and voiding pain scores were lower in the group 4 compared with other groups and there were significant differences at stent removal time in the flank and voiding pain scores among the groups ( $\mathrm{p}$ $=0.013$ and $\mathrm{p}=0.01$, respectively). There was no significant difference in suprapubic pain at the stent removal time between the groups $(\mathrm{p}=0.522)$.

When comparing the differences in total IPSS from the baseline to removal time between paired groups, there were significant differences between group 1 and groups 2, 3 and 4. The irritative subscore showed significant differences between group 1 and groups 3 and 4. The QoL significantly improved in the group 4 compared with that of groups 1 and 2. For pain symptoms, flank pain was the only significantly difference between group 1 and group 4. Additionally, voiding pain was significantly different between group 1 and groups 3 and 4. Only QoL and suprapubic pain significantly improved in those receiving combined-therapy compared with those receiving tolterodine and terazosin alone.

Additionally, we analyzed separately those undergoing TUL, and then the outcomes were similar to the findings when both cohorts were analyzed except voiding pain. The voiding pain before excluding PCNL cohort was significant, while after that it 
Figure 1 - Study flow diagram.

\begin{tabular}{|c|c|c|c|}
\hline & \multicolumn{2}{|c|}{163 Patients assessed for eligibility } & \\
\hline \multicolumn{2}{|c|}{$\begin{array}{l}59 \text { Patients were excluded: } \\
44 \text { Patients met } \\
\text { exclusion criteria } \\
13 \text { Patients did not } \\
\text { undergo stent } \\
\text { Indwelling } \\
2 \text { Patients declined } \\
\text { to participate }\end{array}$} & & \\
\hline \multicolumn{4}{|c|}{104 Patients randomized } \\
\hline \multicolumn{4}{|c|}{\begin{tabular}{|c|c|c|c|} 
& 1 \\
\end{tabular}} \\
\hline $\begin{array}{l}26 \text { Patients } \\
\text { assigned to } \\
\text { receive } \\
\text { placebo }\end{array}$ & $\begin{array}{l}26 \text { Patients } \\
\text { assigned to } \\
\text { receive } \\
\text { terazosin }\end{array}$ & $\begin{array}{l}26 \text { Patients } \\
\text { assigned to } \\
\text { receive } \\
\text { tolterodine }\end{array}$ & $\begin{array}{l}26 \text { Patients } \\
\text { assigned to } \\
\text { receive terazosin } \\
\text { and tolterodine }\end{array}$ \\
\hline 1 & 1 & 1 & 1 \\
\hline $\begin{array}{l}2 \text { Patients } \\
\text { discontinued } \\
\text { study: } \\
1 \text { Intolerable pain } \\
1 \text { Lost to follow up }\end{array}$ & $\begin{array}{l}1 \text { Patient excluded: } \\
\text { Met exclusion } \\
\text { criteria } \\
2 \text { Patients } \\
\text { discontinued } \\
\text { study: } \\
1 \text { Fasting } \\
1 \text { Protocol } \\
\text { deviation }\end{array}$ & $\begin{array}{l}1 \text { Patient excluded: } \\
\text { Stent } \\
\text { displacement } \\
2 \text { Patients } \\
\text { discontinued } \\
\text { study: } \\
2 \text { Lack of efficacy }\end{array}$ & $\begin{array}{l}2 \text { Patients } \\
\text { discontinued } \\
\text { study: } \\
1 \text { Lack of efficacy } \\
1 \text { Withdrew } \\
\text { consent }\end{array}$ \\
\hline I & L & L & L \\
\hline $\begin{array}{l}24 \text { Patients } \\
\text { analyzed }\end{array}$ & $\begin{array}{l}23 \text { Patients } \\
\text { analyzed }\end{array}$ & $\begin{array}{l}23 \text { Patients } \\
\text { analyzed }\end{array}$ & $\begin{array}{l}24 \text { Patients } \\
\text { analyzed }\end{array}$ \\
\hline
\end{tabular}

did not demonstrate significant difference $(p=0.01$ versus $\mathrm{p}=0.157$ ).

The analgesics consumption declined significantly among the groups ( $p=0.02)$, and it was significantly different between group 1 and groups 2 and $4(\mathrm{p}=0.027, \mathrm{p}=0.045$, respectively). These differences did not change even after excluding PCNL patients.

No patients discontinued medications because of side-effects. Furthermore, orthostatic hypotension was reported by thirteen patients (13.8\%), and dry mouth and headache were reported as well; however, there were no significant differences concerning adverse events (Table-3). The mean stenting duration was $15.11 \pm 4.9$ days among the groups and there was no significant difference $(p=0.062)$. It also was not significantly different after analyzing TUL patients alone $(\mathrm{p}=0.123)$.

\section{DISCUSSION}

Despite widespread use of ureteral stent in urologic surgeries, it is associated with morbidities including urinary symptoms, pain and impact on patient QoL $(1,4)$. The etiologies of stent-related symptoms are not fully understood and it is thought that involuntary bladder contraction caused by trigone irritation contributes to urinary bothersome. In addition, increased bladder outlet resistance and pressure during micturition result in urine reflux to the kidneys, which contribute to stent-related flank pain $(16,17)$. Alpha-blockers relieve flank pain by decreasing the muscle tone of the ureter, bladder trigone and prostatic urethra by blocking the alpha-adrenergic receptors and thus reducing bladder outlet resistance and pressure during micturition. Moreover, anticholi- 
Table 1 - Basic and clinical characteristics.

\begin{tabular}{|c|c|c|c|c|c|}
\hline & $\begin{array}{l}\text { Group 1 a } \\
(n=24)\end{array}$ & $\begin{array}{c}\text { Group 2 }{ }^{b} \\
(n=23)\end{array}$ & $\begin{array}{c}\text { Group 3 }{ }^{c} \\
(n=23)\end{array}$ & $\begin{array}{c}\text { Group } 4{ }^{d} \\
(n=24)\end{array}$ & $p$ Value ${ }^{e}$ \\
\hline Age (year) & $33.37 \pm 9.58$ & $38.35 \pm 9.23$ & $37.04 \pm 9.04$ & $35.75 \pm 9.38$ & 0.756 \\
\hline Male & $21(87.5 \%)$ & $16(69.6 \%)$ & $19(82.6 \%)$ & $19(79.2 \%)$ & 0.476 \\
\hline Stone size $(\mathrm{mm})$ & $10.41 \pm 4.66$ & $9.87 \pm 4.33$ & $9.04 \pm 4.15$ & $12.43 \pm 5.53$ & 0.379 \\
\hline Stone place ${ }^{f}$ & & & & & 0.365 \\
\hline Upper ureter & 4 & 4 & 6 & 2 & \\
\hline Mid ureter & 2 & 4 & 0 & 2 & \\
\hline Lower ureter & 15 & 11 & 13 & 12 & \\
\hline Renal pelvis & 0 & 2 & 2 & 5 & \\
\hline Upper calyx & 1 & 0 & 0 & 0 & \\
\hline Mid calyx & 0 & 2 & 1 & 1 & \\
\hline Lower calyx & 2 & 0 & 1 & 2 & \\
\hline Surgery type & & & & & 0.221 \\
\hline TUL & $21(87.5 \%)$ & $19(82.6 \%)$ & $20(86.9 \%)$ & $16(66.6 \%)$ & \\
\hline PCNL & $3(12.5 \%)$ & $4(17.4 \%)$ & $3(13 \%)$ & 8 (33.3\%) & \\
\hline
\end{tabular}

$\mathbf{n}=$ number of subjects; TUL = Transurethral lithotripsy; PCNL = Percutaneous nephrolithotomy

Values are as mean \pm standard deviation and numbers (percentages). ${ }^{a}$ placebo group; ${ }^{b}$ terazosin group; ${ }^{c}$ tolterodine group; ${ }^{\mathrm{d}}$ combined therapy group; ${ }^{\text {e }}$ Chi-squared test was used; ${ }^{\dagger}$ The stone places were grouped in two categories, renal and ureteral stones.

nergics decrease bladder overactivity and contraction by mediating the muscarinic receptors, thereby reducing urinary symptoms $(15,18)$. To the best of our knowledge, this is the first study showing that the combination of terazosin and tolterodine improved stent-related discomforts and decreased consumption of analgesics.

Some investigators have demonstrated $(16,17)$ improving impact of alpha-blockers including alfuzosin and terazosin on stent-related discomforts, whereas Kuyumcuoglu et al. (19) concluded that stent discomforts remained unchanged even after administering doxazosin, therefore, they argued that a new strategy and stent design are required to attenuate stent-related complications; however, a recently published study has demonstrated that the new stents did not improve stent-related symptoms (20). Considering the current study and the two meta-analyses that have been recently published $(21,22)$, it seems that alpha-blockers can effectively relieve stent-related symptoms.

Previous studies $(19,23)$ have shown no impact of anticholinergic on stent discomforts, whereas Lim et al. (15) have demonstrated a reduction in the total IPSS in patients receiving solifenacin compared with those receiving no medication. We believe that the effect of tolterodine on 
Table 2 - Urinary symptoms, pain and QoL among the groups.

\begin{tabular}{|c|c|c|c|c|c|}
\hline & Group 1 & Group 2 & Group 3 & Group 4 & $p$ Value a \\
\hline \multicolumn{6}{|l|}{ Total IPSS score } \\
\hline Baseline & $8.75 \pm 7.37$ & $9.95 \pm 7.67$ & $9.26 \pm 9.00$ & $12.00 \pm 7.57$ & 0.449 \\
\hline Removal time & $11.12 \pm 7.84$ & $4.39 \pm 6.03$ & $7.21 \pm 6.57$ & $5.58 \pm 4.82$ & 0.002 \\
\hline Baseline-TUL alone & $9.33 \pm 7.46$ & $10.32 \pm 8.20$ & $9.20 \pm 9.32$ & $12.37 \pm 6.98$ & 0.417 \\
\hline Removal time- TUL alone ${ }^{b}$ & $11.81 \pm 8.05$ & $5.05 \pm 6.44$ & $6.85 \pm 6.45$ & $5.69 \pm 4.91$ & 0.007 \\
\hline \multicolumn{6}{|l|}{ Irritative subscore } \\
\hline Baseline & $4.12 \pm 3.50$ & $4.17 \pm 4.10$ & $4.65 \pm 4.62$ & $5.58 \pm 4.10$ & 0.600 \\
\hline Removal time & $6.04 \pm 4.18$ & $4.34 \pm 4.23$ & $3.73 \pm 3.48$ & $2.62 \pm 2.37$ & 0.039 \\
\hline Baseline-TUL alone & $4.43 \pm 3.61$ & $4.10 \pm 4.41$ & $4.60 \pm 4.75$ & $5.69 \pm 3.68$ & 0.460 \\
\hline Removal time-TUL alone & $6.48 \pm 4.23$ & $4.63 \pm 4.08$ & $3.70 \pm 4.00$ & $2.81 \pm 2.56$ & 0.041 \\
\hline \multicolumn{6}{|l|}{ Obstructive subscore } \\
\hline Baseline & $4.58 \pm 4.51$ & $5.47 \pm 5.64$ & $4.56 \pm 5.25$ & $6.37 \pm 5.73$ & 0.661 \\
\hline Removal time & $4.95 \pm 4.68$ & $3.91 \pm 5.45$ & $3.56 \pm 4.36$ & $2.95 \pm 3.30$ & 0.251 \\
\hline Baseline-TUL alone & $4.86 \pm 4.55$ & $5.84 \pm 5.95$ & $4.55 \pm 5.50$ & $6.69 \pm 6.20$ & 0.784 \\
\hline Removal time-TUL alone & $5.20 \pm 4.90$ & $3.95 \pm 5.47$ & $3.25 \pm 4.26$ & $2.87 \pm 3.36$ & 0.176 \\
\hline \multicolumn{6}{|l|}{ Flank pain } \\
\hline Baseline & $6.83 \pm 2.64$ & $8.00 \pm 2.86$ & $6.65 \pm 3.39$ & $6.66 \pm 3.70$ & 0.321 \\
\hline Removal time & $4.20 \pm 3.58$ & $3.04 \pm 3.53$ & $2.65 \pm 3.09$ & $1.25 \pm 1.62$ & 0.013 \\
\hline Baseline-TUL alone & $6.95 \pm 2.70$ & $7.84 \pm 2.97$ & $6.75 \pm 3.45$ & $6.87 \pm 4.05$ & 0.609 \\
\hline Removal time-TUL alone & $4.48 \pm 3.71$ & $3.05 \pm 3.40$ & $2.70 \pm 3.23$ & $1.44 \pm 1.75$ & 0.050 \\
\hline \multicolumn{6}{|l|}{ Voiding pain } \\
\hline Baseline & $2.33 \pm 3.26$ & $3.26 \pm 3.68$ & $2.04 \pm 3.33$ & $2.83 \pm 3.33$ & 0.611 \\
\hline Removal time & $4.16 \pm 3.59$ & $3.21 \pm 4.14$ & $1.34 \pm 2.60$ & $1.37 \pm 2.56$ & 0.010 \\
\hline Baseline-TUL alone & $2.43 \pm 3.37$ & $3.00 \pm 3.65$ & $2.10 \pm 3.46$ & $2.69 \pm 3.65$ & 0.853 \\
\hline Removal time-TUL alone & $3.67 \pm 3.51$ & $2.84 \pm 4.11$ & $1.55 \pm 2.74$ & $1.62 \pm 2.90$ & 0.157 \\
\hline \multicolumn{6}{|l|}{ Suprapubic pain } \\
\hline Baseline & $3.58 \pm 2.82$ & $3.21 \pm 3.57$ & $2.69 \pm 3.26$ & $3.66 \pm 3.67$ & 0.674 \\
\hline Removal time & $3.16 \pm 3.86$ & $2.13 \pm 3.62$ & $1.73 \pm 3.06$ & $1.16 \pm 2.20$ & 0.522 \\
\hline Baseline-TUL alone & $4.10 \pm 2.65$ & $2.84 \pm 3.52$ & $3.00 \pm 3.40$ & $3.56 \pm 3.63$ & 0.454 \\
\hline Removal time-TUL alone & $2.95 \pm 3.88$ & $1.58 \pm 3.17$ & $2.00 \pm 3.21$ & $1.50 \pm 2.58$ & 0.664 \\
\hline \multicolumn{6}{|l|}{ QoL } \\
\hline Baseline & $3.29 \pm 1.82$ & $3.73 \pm 1.88$ & $3.69 \pm 2.16$ & $3.83 \pm 2.07$ & 0.609 \\
\hline Removal time & $3.37 \pm 2.16$ & $2.00 \pm 2.25$ & $2.30 \pm 1.89$ & $0.95 \pm 1.12$ & 0.001 \\
\hline Baseline-TUL alone & $3.43 \pm 1.86$ & $3.68 \pm 2.00$ & $3.70 \pm 2.23$ & $4.12 \pm 2.00$ & 0.642 \\
\hline Removal time-TUL alone & $3.38 \pm 2.25$ & $1.79 \pm 1.99$ & $2.25 \pm 2.00$ & $0.87 \pm 1.15$ & 0.002 \\
\hline
\end{tabular}

IPSS = International Prostate Symptom Score; TUL = Transurethral lithotripsy; $\mathbf{Q} \mathbf{o L}=$ quality of life Values are as mean \pm standard deviation. ${ }^{a}$ Kruskal-Wallis test was used; ${ }^{\mathrm{b}}$ TUL alone means analysis after taking away the patients who underwent nephrolithotomy. 
Table 3 - Drug side-effects, narcotics consumption and stenting duration in groups.

\begin{tabular}{|c|c|c|c|c|c|}
\hline & Group 1 & Group 2 & Group 3 & Group 4 & $p$ Value a \\
\hline No of painkiller & $20.73 \pm 12.60$ & $11.45 \pm 8.63$ & $13.86 \pm 10.76$ & $12.25 \pm 11.19$ & 0.021 \\
\hline No of painkiller-TUL alone & $20.10 \pm 13.14$ & $11.17 \pm 9.24$ & $13.70 \pm 10.50$ & $10.5 \pm 7.68$ & 0.026 \\
\hline Tukey b & & 0.027 & 0.151 & 0.045 & \\
\hline Tukey-TUL alone & & 0.052 & 0.226 & 0.039 & \\
\hline Stenting days & $15.38 \pm 5.31$ & $13.48 \pm 2.61$ & $14.35 \pm 3.21$ & $17.13 \pm 6.70$ & 0.062 \\
\hline Stenting days-TUL alone & $14.67 \pm 4.57$ & $13.00 \pm 2.05$ & $13.75 \pm 2.34$ & $16.56 \pm 7.63$ & 0.123 \\
\hline \multicolumn{6}{|l|}{ Drug side-effects } \\
\hline Orthostatic hypotension & 2 & 4 & 1 & 6 & 0.168 \\
\hline Headache & 2 & 1 & 0 & 2 & 0.938 \\
\hline Dry mouth & 1 & 1 & 2 & 3 & 0.662 \\
\hline
\end{tabular}

Values are as mean \pm standard deviation and numbers. ${ }^{\mathrm{a}}$ One-way ANOVA test was used; ${ }^{\mathrm{b}}$ Tukey HSD test was used to determine the differences between group 1 and groups 2,3 and 4 .

urinary symptoms may be caused by either informing the patients about the possible increase in symptoms by activity that could reduce activities of daily living and consequent trigone irritation by the stent tail or blockade of muscarinic receptors by tolterodine. The suprapubic pain is also caused by trigone irritation from the stent tail (3), but it was not alleviated. It is a curious paradox that tolterodine attenuated urinary symptoms but does not affect suprapubic pain, hence, we think that these results may be caused by either the sample size or an unknown mechanism that requires further investigations to clarify.

The patients receiving combined-therapy experienced significant reductions in the total IPSS, irritative subscore, flank and voiding pains, analgesic counts, and QoL compared with those receiving placebo. Recently, two investigations $(6,15)$ assessed the impact of alpha-blocker/anticholinergic on stent-related symptoms. One study showed stent position is more important than medical therapy, and the other found that combined- -therapy improved the urinary symptoms and QoL but did not improve pain.

Unfortunately, randomization led to more number of patients who underwent PCNL in the combined-therapy compared with placebo group (33\% vs. 12\%). However, regardless of whether the patients underwent TUL or PCNL, they were submitted to ureteroscopy or cystoscopy for stenting, therefore, the flank pain might be the only different symptom between both cohorts, and the lower urinary tract symptoms might be the same for those. We conclude that the significant improvement in the flank pain in the combined-therapy compared with placebo group may be explained by this notion. Furthermore, we excluded the PCNL patients and analyzed only TUL cohort that demonstrated similar outcomes except voiding pain.

Some studies concerning the stent position have argued that crossing the stent distal apart from bladder midline was significantly related to ureteral stent discomforts $(7,24)$. Considering this 
issue, all of the patients in the present study underwent X-ray imaging after stenting to confirm the proper stent placement. Although all patients had correct stent placement at discharge, one patient in tolterodine group complained of intolerable pain three days following the stenting and underwent further evaluation for pain; the patient was excluded because of stent displacement.

This study had some limitations. First, we applied stents with the same size and length; however, some studies have shown that the stent length is associated with stent-related symptoms (8), and others have revealed that it did not have any impact on stent discomforts $(25,26)$. Given this point, we used same stents, although we could also use different size of stents proportionate to the patients' length. Second, the stenting duration was different among the groups but it was not significant ( $p=0.06$ ); however, Irani et al. (26) demonstrated that stent-related symptoms after some days remained unchanged. Third, we used the IPSS to evaluate urinary symptoms, but Joshi et al. (27) have developed a specific tool for assessing stent-related symptoms which is named "ureteric stent symptoms questionnaire" (USSQ). Although, it has been previously implemented, we could not apply it due to lack of translation to our local language and its validity and reliability.

\section{CONCLUSIONS}

The use of terazosin $2 \mathrm{mg}$ twice daily plus tolterodine $2 \mathrm{mg}$ once daily in patients with unilateral stenting significantly improved stent-related urinary symptoms; especially irritative symptoms; pain and QoL; and decreased the amount of analgesic use. Further prospective, large-scale studies are required to evaluate the effects of other alpha-blockers/anticholinergics concerning management of stent-related discomforts.

\section{ABBREVIATIONS}

IPSS = International Prostate Symptom Score

QoL $=$ Quality of life

TUL $=$ Transurethral lithotripsy

PCNL = Percutaneous nephrolithotomy

USSQ $=$ Ureteric stent symptoms questionnaire

\section{CONFLICT OF INTEREST}

\author{
None declared.
}

\section{REFERENCES}

1. Chew BH, Knudsen BE, Denstedt JD: The use of stents in contemporary urology. Curr Opin Urol. 2004; 14: 111-5.

2. Haleblian G, Kijvikai K, de la Rosette J, Preminger G: Ureteral stenting and urinary stone management: a systematic review. J Urol. 2008; 179: 424-30.

3. Miyaoka R, Monga M: Ureteral stent discomfort: Etiology and management. Indian J Urol. 2009; 25: 455-60.

4. Joshi HB, Stainthorpe A, MacDonagh RP, Keeley FX Jr, Timoney AG, Barry MJ: Indwelling ureteral stents: evaluation of symptoms, quality of life and utility. J Urol. 2003; 169: 10659; discussion 1069.

5. Damiano R, Oliva A, Esposito C, De Sio M, Autorino R, D'Armiento M: Early and late complications of double pigtail ureteral stent. Urol Int. 2002; 69: 136-40.

6. Lee SJ, Yoo C, Oh CY, Lee YS, Cho ST, Lee SH, et al.: Stent Position Is More Important than $\alpha$-Blockers or Anticholinergics for Stent-Related Lower Urinary Tract Symptoms after Ureteroscopic Ureterolithotomy: A Prospective Randomized Study. Korean J Urol. 2010; 51: 636-41.

7. Giannarini G, Keeley FX Jr, Valent F, Manassero F, Mogorovich A, Autorino R, et al.: Predictors of morbidity in patients with indwelling ureteric stents: results of a prospective study using the validated Ureteric Stent Symptoms Questionnaire. BJU Int. 2011; 107: 648-54.

8. Al-Kandari AM, Al-Shaiji TF, Shaaban H, Ibrahim HM, Elshebiny YH, Shokeir AA: Effects of proximal and distal ends of double-J ureteral stent position on postprocedural symptoms and quality of life: a randomized clinical trial. $J$ Endourol. 2007; 21: 698-702.

9. Lingeman JE, Preminger GM, Goldfischer ER, Krambeck AE; Comfort Study Team: Assessing the impact of ureteral stent design on patient comfort. J Urol. 2009; 181: 2581-7.

10. Ecke TH, Bartel P, Hallmann S, Ruttloff J: Evaluation of symptoms and patients' comfort for JJ-ureteral stents with and without antireflux-membrane valve. Urology. 2010; 75: 212-6.

11. Kaplan SA, Roehrborn CG, Rovner ES, Carlsson M, Bavendam T, Guan Z: Tolterodine and tamsulosin for treatment of men with lower urinary tract symptoms and overactive bladder: a randomized controlled trial. JAMA. 2006; 296: 2319-28. Erratum in: JAMA. 2007; 298: 1864.

12. Chapple C, Herschorn S, Abrams P, Sun F, Brodsky M, Guan Z: Tolterodine treatment improves storage symptoms suggestive of overactive bladder in men treated with alpha-blockers. Eur Urol. 2009; 56: 534-41. 
13. Blake-James BT, Rashidian A, Ikeda Y, Emberton M: The role of anticholinergics in men with lower urinary tract symptoms suggestive of benign prostatic hyperplasia: a systematic review and meta-analysis. BJU Int. 2007; 99: 85-96.

14. Park SC, Jung SW, Lee JW, Rim JS: The effects of tolterodine extended release and alfuzosin for the treatment of double-j stent-related symptoms. J Endourol. 2009 ; 23: 1913-7.

15. Lim KT, Kim YT, Lee TY, Park SY: Effects of tamsulosin, solifenacin, and combination therapy for the treatment of ureteral stent related discomforts. Korean J Urol. 2011; 52: 485-8.

16. Beddingfield R, Pedro RN, Hinck B, Kreidberg C, Feia K, Monga M: Alfuzosin to relieve ureteral stent discomfort: a prospective, randomized, placebo controlled study. J Urol. 2009; 181: 170-6.

17. Mokhtari G, Shakiba M, Ghodsi S, Farzan A, Heidari Nejad S, Esmaeili S: Effect of terazosin on lower urinary tract symptoms and pain due to double-J stent: a double-blind placebocontrolled randomized clinical trial. Urol Int. 2011; 87: 19-22.

18. Deliveliotis C, Chrisofos M, Gougousis E, Papatsoris A, Dellis A, Varkarakis IM: Is there a role for alpha1-blockers in treating double-J stent-related symptoms? Urology. 2006; 67: 35-9.

19. Kuyumcuoglu U, Eryildirim B, Tuncer M, Faydaci G, Tarhan F, Ozgül A: Effectiveness of medical treatment in overcoming the ureteral double-J stent related symptoms. Can Urol Assoc J. 2012; 6: E234-7.

20. Davenport K, Kumar V, Collins J, Melotti R, Timoney AG, Keeley FX Jr: New ureteral stent design does not improve patient quality of life: a randomized, controlled trial. J Urol. 2011; 185: $175-8$.

21. Lamb AD, Vowler SL, Johnston R, Dunn N, Wiseman OJ: Meta-analysis showing the beneficial effect of $\alpha$-blockers on ureteric stent discomfort. BJU Int. 2011; 108: 1894-902.
22. Yakoubi R, Lemdani M, Monga M, Villers A, Koenig P: Is there a role for $\alpha$-blockers in ureteral stent related symptoms? A systematic review and meta-analysis. J Urol. 2011; 186: 928-34.

23. Norris RD, Sur RL, Springhart WP, Marguet CG, Mathias BJ, Pietrow PK,et al.: A prospective, randomized, double-blinded placebo-controlled comparison of extended release oxybutynin versus phenazopyridine for the management of postoperative ureteral stent discomfort. Urology. 2008; 71: 792-5.

24. Rane A, Saleemi A, Cahill D, Sriprasad S, Shrotri N, Tiptaft R: Have stent-related symptoms anything to do with placement technique? J Endourol. 2001; 15: 741-5.

25. Damiano R, Autorino R, De Sio M, Cantiello F, Quarto G, Perdonà $S$, et al.: Does the size of ureteral stent impact urinary symptoms and quality of life? A prospective randomized study. Eur Urol. 2005; 48: 673-8.

26. Irani J, Siquier J, Pirès C, Lefebvre 0 , Doré B, Aubert J: Symptom characteristics and the development of tolerance with time in patients with indwelling double-pigtail ureteric stents. BJU Int. 1999; 84: 276-9.

27. Joshi HB, Newns N, Stainthorpe A, MacDonagh RP, Keeley FX Jr, Timoney AG: Ureteral stent symptom questionnaire: development and validation of a multidimensional quality of life measure. J Urol. 2003; 169: 1060-4.

Correspondence address:

Yousef Rezaei, MD

Students' Research Committee,

Urmia University of Medical Sciences Urmia, Iran

Fax: + $98441293-0800$

E-mail: yousefrezaei1986@gmail.com 